\title{
Analytical model of stress field in submerged arc welding butt joint with thorough penetration
}

\author{
Jerzy Winczek ${ }^{1, *}$, Ryszard Parkitny ${ }^{2}$, Krzysztof Makles ${ }^{1}$, Marcin Kukuryk ${ }^{1}$ \\ ${ }^{1}$ Czestochowa University of Technology, 42-201 Czestochowa, Poland \\ ${ }^{2}$ Katowice School of Technology, 40-555 Katowice, Poland
}

\begin{abstract}
Analytical model of temporary and residual stresses for butt welding with thorough penetration was described assuming planar section hypothesis and using integral equations of stress equilibrium of the bar and simple Hooke's law. In solution the effect of phase transformations (structure changes and structural strains) has been taken into account. Phase transformations during heating are limited by temperature values at the beginning and at the end of austenitic transformation, depending on chemical composition of steel while the progress of phase transformations during cooling is determined on the basis of TTT-welding diagram. Temperature values at the beginning and at the end of transformation are conditioned by the speed of heating. Kinetics of diffusional transformation is described basing on Johnson-MehlAvrami-Kolmogorov equation, while martensitic transformation, basing on KoistinenMarburger equation. Stresses in elasto-plastic state are determined by iteration, using elastic solutions method with changeable longitudinal modulus of elasticity, conditioned by stress-strain curve. Computations of stress field have been conducted for one-side butt welded of two steel flats made from S235 steel. It has enabled a clear interpretation of influence of temperature field and phase transformation on stresses caused by welding using Submerged Arc Welding (SAW) method.
\end{abstract}

Keywords: modeling, welding, temperature field, phase transformations, stresses

\section{Introduction}

Modeling of thermomechanical states during welding requires the determination of temperature field. It is necessary to calculate the shares of structural elements taking into account their changes that occur as a result of phase transformations. Finally the thermal and structural strains enable the determination of temporary and residual stresses.

Modeling the temperature field in many technological processes requires the movement heat source taking into account. Such an approach is found in descriptions of temperature fields in welding processes [1-15], as well as in the machining processes [16-19]. In modelling of temperature field during welding dominate two approaches: analytical [1-6] and numerical [7-15].

Works refering to stress state analysis during welding, are mainly based on FEM (Finite Element Method) and experimental research. In most publications on FEM techniques for

\footnotetext{
*Corresponding author: winczek@imipkm.pcz.pl

Reviewers: Ladislav Écsi, Janusz Mielniczuk
} 
welding, a homogeneous model of the material with the thermo-mechanical properties dependent on temperature is adopted. The effect of phase transformation in the solid state has been taken into consideration among others in [20-24].

\section{Computational model of stress states}

The analysis of the stress state was performed for steel rectangular elements whose dimension in the direction of welding dominates over the transverse dimensions. The stress state of the elements, for which considerations relating to the stress state of rods were used, is approximately uniaxial.

Considered element is freely supported and exposed to mechanical (thermal) loads which for particular $x$ cross sections are characterized by the internal forces (sectional) $N=$ $N(x), M_{y}=M_{y}(x)$ and $M_{z}=M_{z}(x)$. Other sectional forces will be regarded as small (shear forces $\left.T_{y}=T_{y}(x), T_{z}=T_{z}(x)\right)$, or not occuring $\left(M_{x}=M_{x}(x)\right)$. The element is also subjected to the temperature field $T=T(x, y, z, t)$.

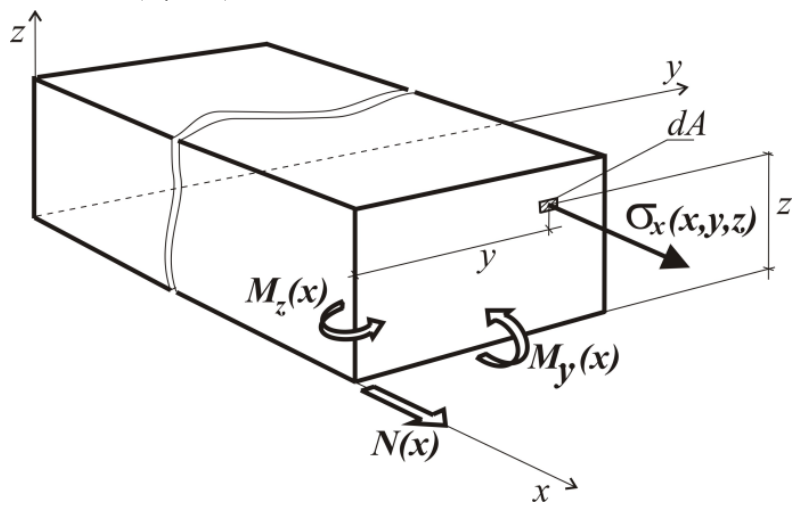

Fig. 1. Scheme of the element subjected to mechanical and thermal loads

Stress state of the element is characterized by one-dimensional stress state $\sigma_{x}=$ $\sigma_{x}(x, y, z, t)$ (Fig. 1), which meets the requirement of the integral equations of stress equilibrium:

$$
\begin{aligned}
& \int_{(A)} \sigma_{x} d A=N \\
& \int_{(A)} \sigma_{x} y d A=-M_{z} \\
& \int_{(A)} \sigma_{x} z d A=-M_{y}
\end{aligned}
$$

The other three integral equations of equilibrium:

$$
\begin{aligned}
& \int_{(A)} \tau_{x y} d A=T_{y} \\
& \int_{(A)} \tau_{x z} y d A=T_{z} \\
& \int_{(A)}\left(-\tau_{x y} z+\tau_{x z} y\right) d A=M_{x}
\end{aligned}
$$

are omitted due to the minimal sectional forces $T_{y}, T_{z}$ and $M_{x}$. 
Cauchy relations were used and the plane cross section hypothesis was adopted in order to introduce stress formulas and element displacements. It was assumed that the crosssections of the element are subject only to the translation and rotation and do not undergo deplanation or deformations in their plane. The assumption of cross-sectional rigidity of the element in consequence imposes the necessity of proving that linear and angular deformation in the plane are equal to zero. Poisson's ratio also adopts value zero, crosssections do not respond to lengthening or shortening of the element longitudinal fibers. Displacements of individual cross sections are defined by three translation vectors $u_{0}=$ $u_{0}(x), v_{0}=v_{0}(x)$ and $w_{0}=w_{0}(x)$ at axis $x$, with $x, y$ and $z$ directions respectively. These displacements are defined as element axial displacement and the element axis deflection in the $y$ and $z$ direction respectively. In the following considerations the geometrical axis of the element is closely related to the axis $x$. Displacement field of the points that define cross-sections of the element is described by linear dependencies, with the following restrictions:

- displacement field of the element is kinematically allowed (the strains inseparability equations are fulfilled),

- postulated element strain $\varepsilon_{x}$ is small $(\varepsilon<<1)$.

In the present case, in accordance with technical bendig beam theory, we do not use differential equilibrium equations but only the integral equilibrium equations and the simple Hooke's law $\sigma_{x}=E \varepsilon_{x}$, which is equivalent to accepting linear-elastic body in constitutive relations. Therefore:

$$
\sigma_{x}=E\left(u_{0}^{\prime}-v_{0}^{\prime \prime} y-w_{0}^{\prime \prime} z-\alpha T\right)
$$

and the integral equilibrium conditions (1) will be written in the form:

$$
\begin{aligned}
& \int_{(A)} E\left(u_{0}^{\prime}-v_{0}^{\prime \prime} y-w_{0}^{\prime \prime} z-\alpha T\right) d A=N \\
& \int_{(A)} E\left(u_{0}^{\prime}-v_{0}^{\prime \prime} y-w_{0}^{\prime \prime} z-\alpha T\right) y d A=-M_{z} \\
& \int_{(A)} E\left(u_{0}^{\prime}-v_{0}^{\prime \prime} y-w_{0}^{\prime \prime} z-\alpha T\right) z d A=-M_{y}
\end{aligned}
$$

Bearing in mind that element axis displacements $u_{0}, v_{0}$ and $w_{0}$ are solely the functions of the variable $x$, under integral values are symbolically saved as:

$$
\begin{array}{r}
A^{E}=\int_{(A)} E d A \quad S_{y}^{E}=\int_{(A)} E z d A \quad S_{z}^{E}=\int_{(A)} E y d A \quad J_{y z}^{E}=\int_{(A)} E y z d A \quad J_{y}^{E}=\int_{(A)} E z^{2} d A \\
J_{z}^{E}=\int_{(A)} E y^{2} d A \quad N^{T}=\int_{(A)} \alpha E T d A \quad M_{y}^{T}=\int_{(A)} \alpha E T z d A \quad M_{z}^{T}=\int_{(A)} \alpha E T y d A
\end{array}
$$

for elastic modulus which is variable with respect to the coordinates (non-homogeneous element material) or temperature-dependent Young`s modulus, after solving the equations system (4), stresses defined by formula (3) will be written as:

$$
\sigma_{x}=E\left(\left(N+N^{T}\right) \frac{\Delta_{N}}{\Delta}+\left(M_{y}+M_{y}^{T}\right) \frac{\Delta_{M_{y}}}{\Delta}+\left(-M_{z}+M_{z}^{T}\right) \frac{\Delta_{M_{z}}}{\Delta}-\alpha T\right)
$$

where:

$$
\Delta_{N}=J_{y}^{E} J_{z}^{E}-\left(J_{y z}^{E}\right)^{2}+\left(S_{y}^{E} J_{y z}^{E}-S_{z}^{E} J_{y}^{E}\right) y+\left(S_{z}^{E} J_{y z}^{E}-S_{y}^{E} J_{z}^{E}\right) z
$$




$$
\begin{aligned}
& \Delta_{M y}=S_{z}^{E} J_{y z}^{E}-S_{y}^{E} J_{z}^{E}+\left(S_{y}^{E} S_{z}^{E}-A^{E} J_{y z}^{E}\right) y+\left(A^{E} J_{z}^{E}-\left(S_{z}^{E}\right)^{2}\right) z \\
& \Delta_{M z}=S_{y}^{E} J_{y z}^{E}-S_{z}^{E} J_{z}^{E}+\left(A^{E} J_{y}^{E}-\left(S_{y}^{E}\right)^{2}\right) y+\left(S_{y}^{E} S_{z}^{E}-A^{E} J_{y z}^{E}\right) z \\
& \Delta=A^{E} J_{y}^{E} J_{z}^{E}+2 S_{y}^{E} S_{z}^{E} J_{y z}^{E}-\left(S_{y}^{E}\right)^{2} J_{z}^{E}-\left(S_{z}^{E}\right)^{2} J_{y}^{E}-A^{E}\left(J_{y z}^{E}\right)^{2}
\end{aligned}
$$

The stresses in elasto-plastic state are determined by iteration using the method of elastic solutions at the variable modulus of longitudinal elasticity conditioned by the stressstrain curve [25].

\section{Example of computations}

In the considered example it is assumed that the welded material is steel S235 with the following material properties: specific heat $C_{p}=670 \mathrm{~J} /(\mathrm{kg} \cdot \mathrm{K})$, density $\rho=7800 \mathrm{~kg} / \mathrm{m}^{3}$, thermal diffusivity $a=1.2 \times 10^{-5} \mathrm{~m}^{2} / \mathrm{s}$, the temperatures of the beginning and end of austenite transformation, respectively $A_{1}=996 \mathrm{~K}\left(723{ }^{\circ} \mathrm{C}\right)$ and $A_{3}=1108 \mathrm{~K}\left(835^{\circ} \mathrm{C}\right)$, solidus temperature $T_{S}=1763 \mathrm{~K}\left(1490{ }^{\circ} \mathrm{C}\right)$ and the liquidus temperature $T_{L}=1793 \mathrm{~K}$ $\left(1520{ }^{\circ} \mathrm{C}\right)$. The model of joining two butt welded flats with length $1 \mathrm{~m}$, a thickness of $0.012 \mathrm{~m}$ and a width of $0.1 \mathrm{~m}$ as shown in Fig. 2 .

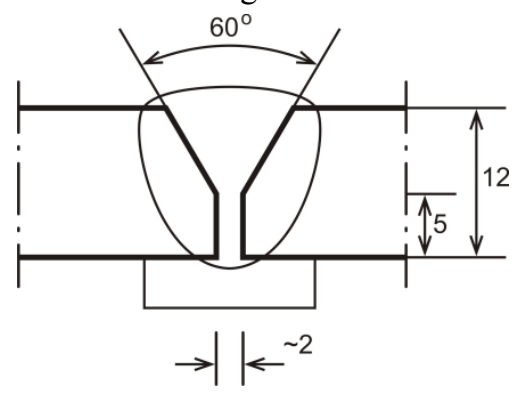

Fig. 2. Scheme of the welded joint with technology chamfering

Numerical simulations were performed with author's program created in Borland Delphi environment using Borland Pascal language. Near the control area (cross section $\mathrm{x}=0.5 \mathrm{~m}$ ) calculations were performed with time step $0.05 \mathrm{~s}$. Calculations with such time increase are necessary due to the high heating rates, as well as reaching maximum temperature at particular points of surfaced object at different times of the deposition process. In the anticipated areas and the heat affected zone temperature calculations were made at points in the distances of $0.5 \mathrm{~mm}$, increasing the distance further from the HAZ at the edges of the flat calculation were performed every $5 \mathrm{~mm}$.

The calculations were performed assuming the speed of movement source $v=$ $0.005 \mathrm{~m} / \mathrm{s}$, and its power $P=18000 \mathrm{~W}$. Three-dimensional temporary field for butt welding with thorough penetration was described on the basis of analytical methods proposed by Geissler and Bergmann [26, 27] of an integral transformation and Green's function. The results of the temperature field calculations are presented in [28] as well as the boundaries of the heat-affected zones (fusion line, full and partial transformation zones) (Fig. 3). In the figure, the selected points of cross section were marked, for which a detailed analysis of welding thermal cycles and stresses were performed. 


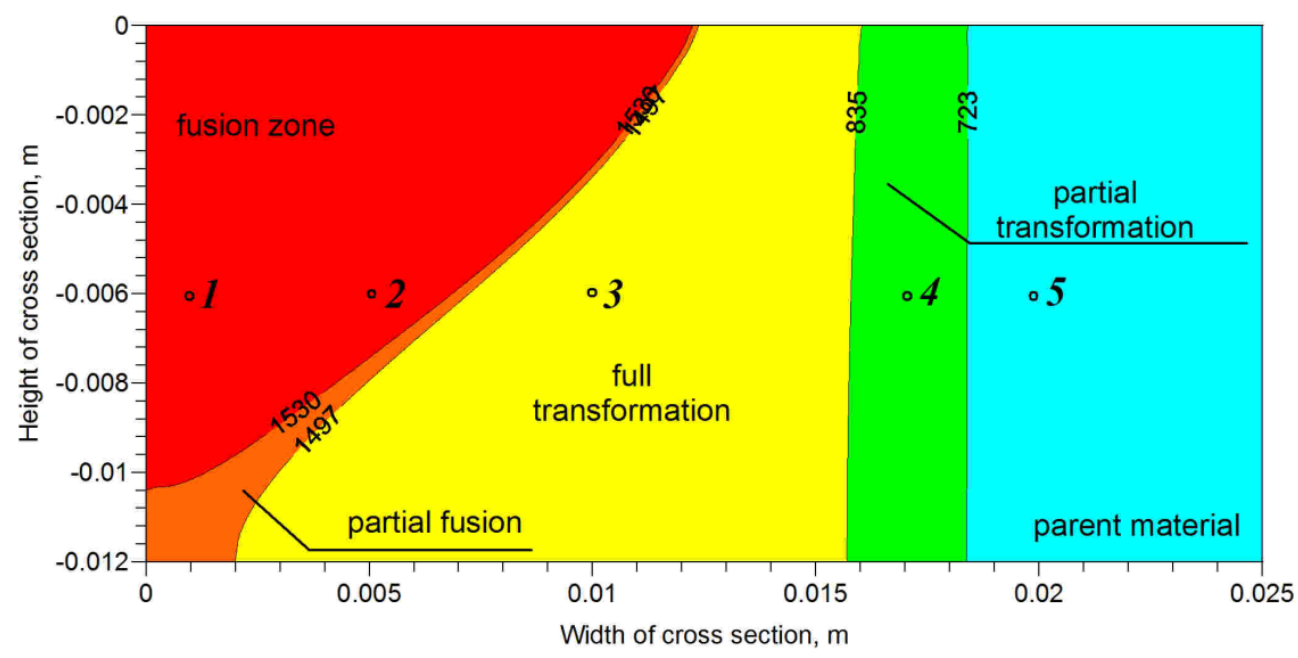

Fig. 3. Heat affected zones [25]

In calculations the effect of phase transformations (structure changes and structural strains) has been taken into account. Phase transformations during heating are limited by temperature values at the beginning and at the end of austenitic transformation, depending on chemical composition of steel while the progress of phase transformations during cooling is determined on the basis of TTT-welding diagram. Temperature values at the beginning and at the end of transformation are conditioned by the speed of heating. Kinetics of diffusional transformation is described basing on Johnson-Mehl-Avrami-Kolmogorov equation [29, 30], while martensitic transformation, basing on Koistinen-Marburger equation [31]. The calculation results of the volume fraction of the structural constituents, also thermal and structural deformations are discussed in [32]. This was the basis for the stress calculation - temporary and residual.

In strain calculations there was assumed linear expansion coefficients of particular structural elements and structural stresses (Tab. 1) determined on the basis of the dilatometric research $[33,34]$.

Table 1. Structural $(\gamma)$ and thermal $(\alpha)$ expansion coefficients of phases

\begin{tabular}{|l|c|c|c|}
\hline & $\alpha\left[\mathbf{1} /{ }^{\circ} \mathbf{C}\right]$ & & $\gamma$ \\
\hline Austenite & $2.178 \cdot 10^{-5}$ & $\gamma_{\mathrm{F}, \mathrm{P}, \mathrm{S} \rightarrow \mathrm{A}}$ & $1.986 \cdot 10^{-3}$ \\
\hline Ferrite & $1.534 \cdot 10^{-5}$ & $\gamma_{\mathrm{B} \rightarrow \mathrm{A}}$ & $1.440 \cdot 10^{-3}$ \\
\hline Pearlite & $1.534 \cdot 10^{-5}$ & $\gamma_{\mathrm{A} \rightarrow \mathrm{F}, \mathrm{P}}$ & $3.055 \cdot 10^{-3}$ \\
\hline Bainite & $1.171 \cdot 10^{-5}$ & $\gamma_{\mathrm{A} \rightarrow \mathrm{B}}$ & $4.0 \cdot 10^{-3}$ \\
\hline Martensite & $1.36 \cdot 10^{-5}$ & \multicolumn{3}{|l}{} \\
\hline
\end{tabular}

Tensile curves of ferrite and pearlite are assumed on the basis of works [35, 36]. In case of austenite, bainite and martensite on the basis of data from works [37, 38] tensile curves are determined according to Swift law [39].

Residual stresses distribution in the whole right half of joint cross-section has been presented in Fig. 4, while the stresses in the heat affected zone have been presented in Fig. 5. Residual stresses distribution is distinguished by high values of tensile stresses in weld and heat affected zones. In the parent material area (outside heat affected zone) compressive stress state occurs. In fusion and full transformation areas tensile stress values are determined by plastic strains. In remaining areas of parent material, stress state is determined by maintenance of stress equilibrium in the cross-section. 


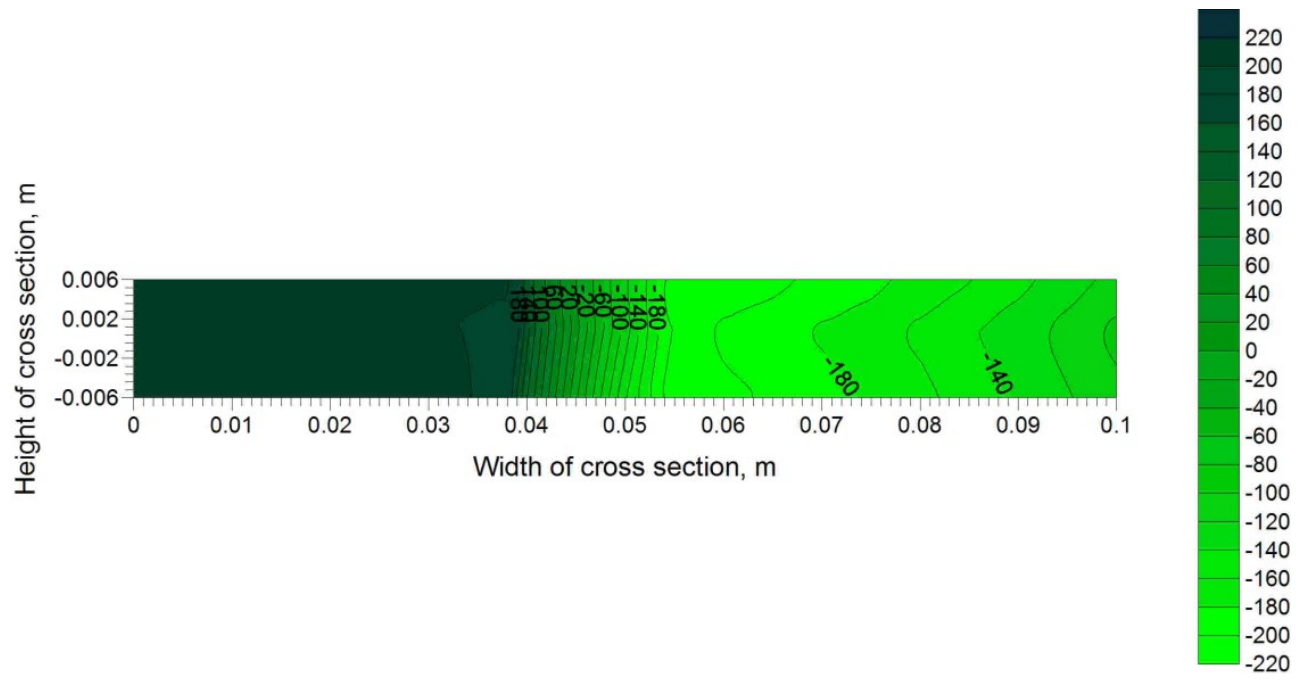

Fig. 4. Residual stress distribution in the whole right half of joint cross-section

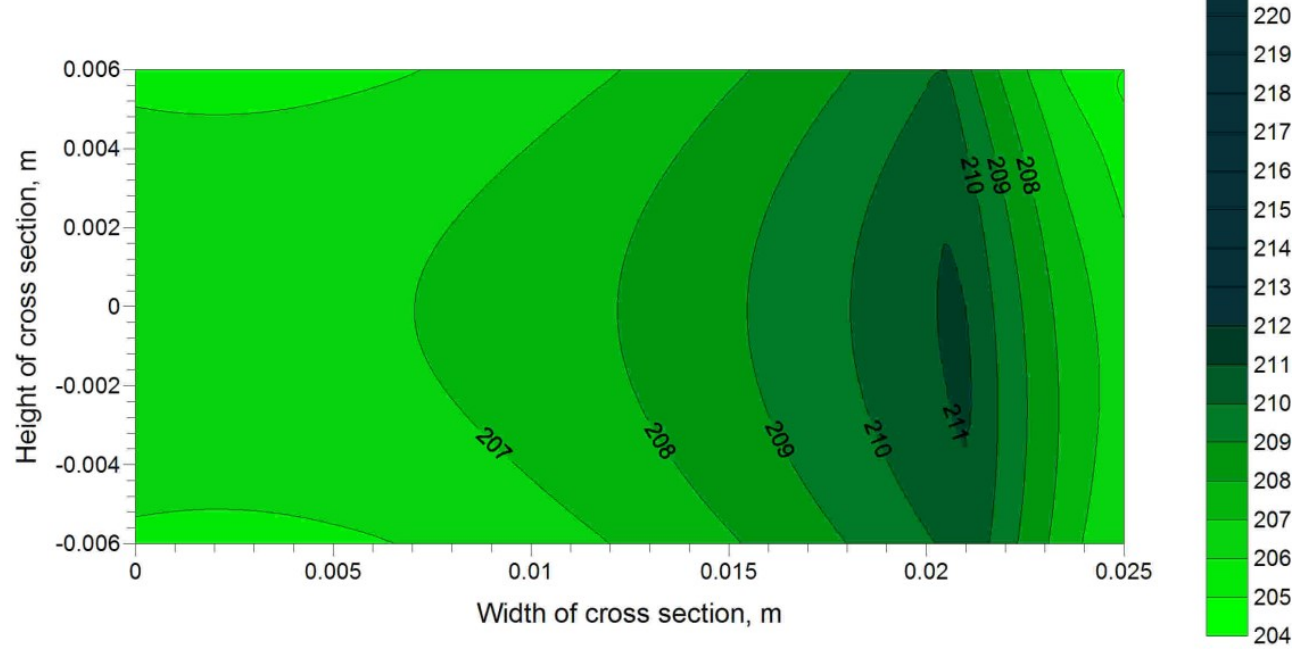

Fig. 5. Residual stress distribution in the heat affected zones

In figures $6-11$ the history of temperature and stress changes at selected points of cross section has been presented (comp. Fig. 3). At point 1 from the weld area (groove weld) (Fig. 6), stresses amount to zero as long as the point is in a state of liquid metal. After solidification during cooling tensile stresses increase. Sudden transformation of stresses into compressive is caused by phase transformation. At point 2 from fusion zone (Fig. 7) due to heating compressive stresses increase. During transformation of initial structure into austenite stresses become tensile, but then during melting they vanish. After solidification the history of stress changes is similar to that at point 1. At point 3 (Fig. 8) from the area of full transformation due to the heating compressive stresses occur. Then, likewise at point 2, due to transformation of initial structure into austenite, stress state changes into tensile. Next, tensile stresses, being under the influence of further temperature growth, decrease but during cooling stresses increase again. During phase transformations of overcooled austenite into ferrite and pearlite stresses plunge becoming compressive. Then during 
further cooling compressive stresses decrease but values of tensile stresses increase. At point 4 (Fig. 9) from the area of partial transformation during heating compressive stresses increase, but then due to austenitization transform into tensile. During transformation cooling, what causes further, much slower growth of tensile stresses. Transformations during cooling cause the decrease in values of tensile stresses and change of their sign. After phase transformations, due to further cooling, compressive stresses decrease, while tensile start to increase. At point 5 (Fig. 10) and at point 6 with coordinates $(0.09,0)$ (Fig. 11) from the parent material area change of stress states results from temperature changes, changes of yield stress and from stress equilibrium in the cross-section. Compressive stresses increase during heating but decrease during cooling, becoming tensile.
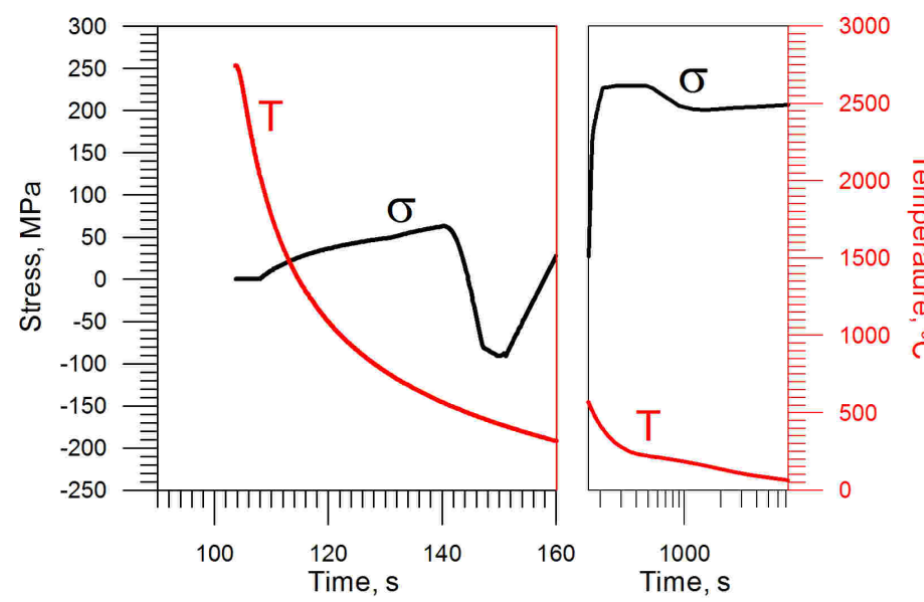

Fig. 6. Thermal cycle and stresses during welding at point 1
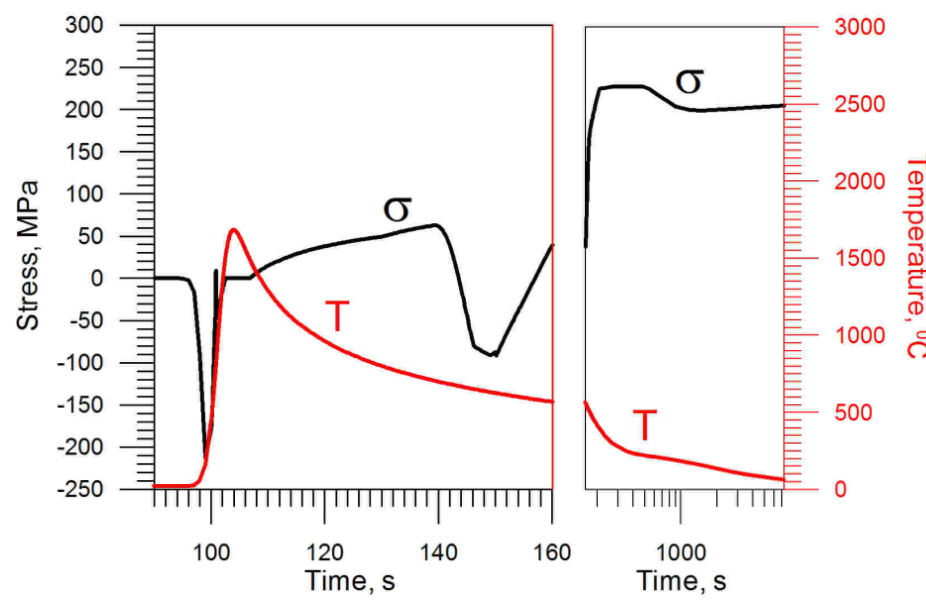

Fig. 7. Thermal cycle and stresses during welding at point 2 

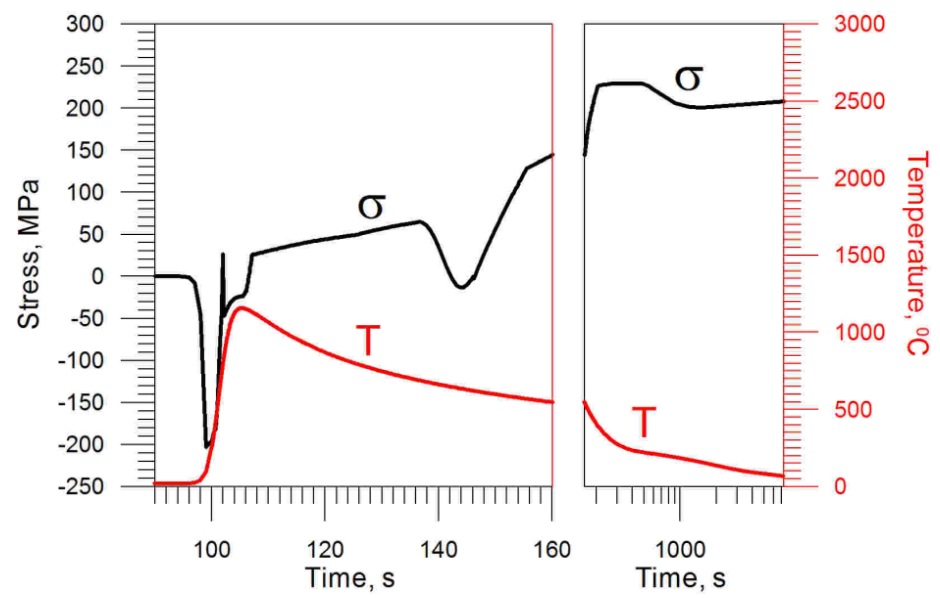

Fig. 8. Thermal cycle and stresses during welding at point 3

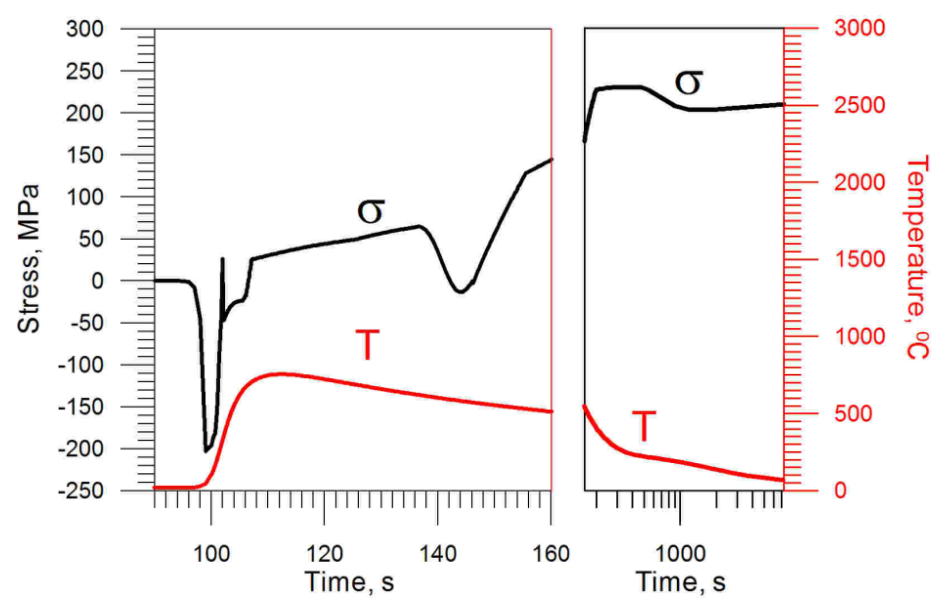

Fig. 9. Thermal cycle and stresses during welding at point 4

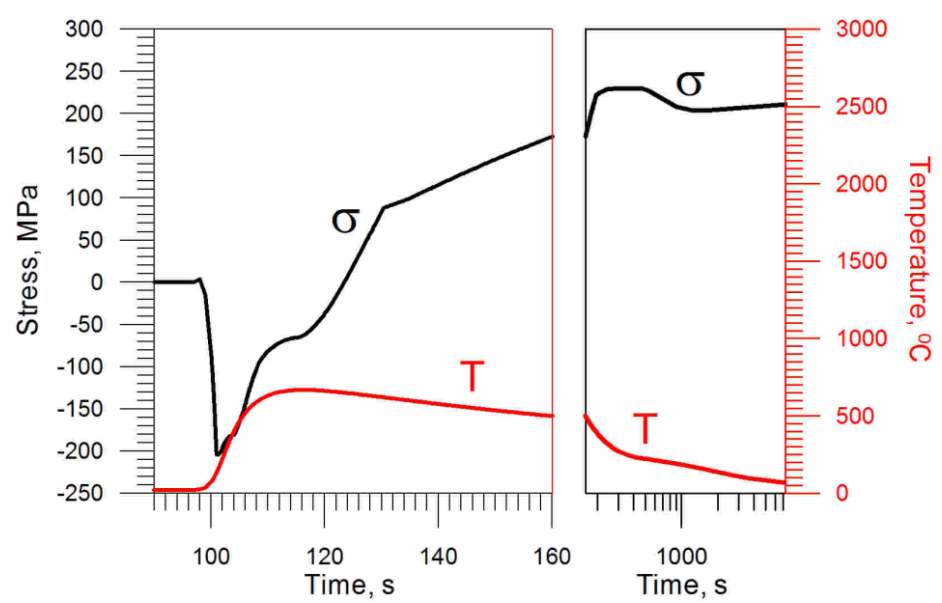

Fig. 10. Thermal cycle and stresses during welding at point 5 


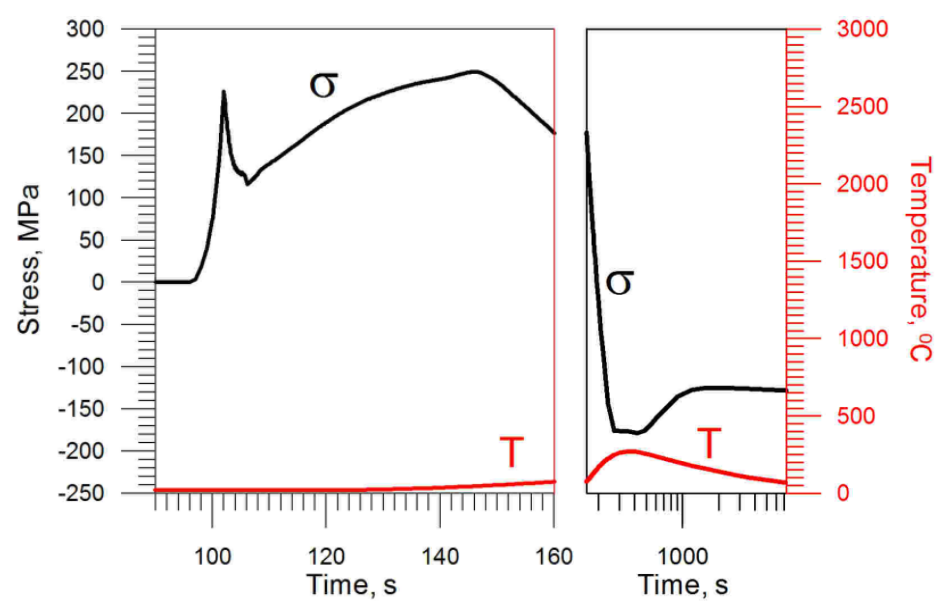

Fig. 11. Thermal cycle and stresses during welding at point 6

\section{Conclusions}

Calculated state of residual normal stresses after welding is characterised by high values of tensile stresses in weld, fusion and full transformation zones as well as by a sudden decrease of their values in partial transformation zone. Whereas in parent material areas outside heat affected zone compressive stresses occur. Correctness of such residual stress distribution was proved by experimental results presented in literature.

The obtained results of numerical simulations confirm the correctness of models and author's programs. They provide the basis for modeling of thermomechanical states during welding used in industrial practice.

\section{References}

1. R. N. S. Fassani, O. V. Trevisan, Analytical modeling of multipass welding process with distributed heat source. J. Braz. Soc. Mech. Sci. Eng. 25, 302-305 (2003)

2. A. Ghosh, N. Barman; H. Chattopadhyay, S. Hloch, A study of thermal behaviour during submerged arc welding. Stroj. Vest. J. Mech. Eng. 59, 333-338 (2013)

3. A. Franco, L. Romoli, A. Musacchio, Modelling for predicting seam geometry in laser beam welding of stainless steel. Int. J. Therm. Sci. 79, 194-205 (2014)

4. V. D. Fachinotti, A. A. Anca, A. Cardona, Analytical solutions of the thermal field induced by moving double-ellipsoidal and double elliptical heat sources in a semiinfinite body. Int. J. Num. Meth. Biomech. Eng. 27, 595-607 (2011)

5. T. Antonakakis, C. Maglioni, V. Vlachoudis, Closed form solutions of the heat diffusion equation with Gaussian source. Int. J. Heat Mass Transf. 62, 314-322 (2013)

6. S. Salimi, P. Bahemmat, M. Haghpanahi, A 3D transient analytical solution to the temperature field during dissimilar welding processes. Int. J. Mechn. Sci. 79, 66-74 (2014)

7. S. Joshi, C. Semetay, J. W. H. Price, H. F. Nied, Weld-induced residual stresses in a prototype dragline cluster and comparison with design codes. Thin Wall. Struct. 48, 89-102 (2010) 
8. J. Hildebrand, I. Starcevic, F. Werner, H. Heinemann, G. Köhler, Numerical simulation of TIG-dressing of welded joints. Joint Int. Conf. Comput. Decision Making Civil Building Eng., Montreal, Canada, 1487-1496 (2006)

9. M. M. Mahapatra, G. L. Datta, B. Pradhan, Three-dimensional finite element analysis to predict the effects of shielded metal arc welding process parameters on temperature distributions and weldment zones in butt and one-sided fillet welds. P. I. Mech. Eng. B J. Eng. 220, 837-845 (2006)

10. S. Joshi, J. Hildebrand, A. S. Aloraier, T. Rabczuk, Characterization of materiat properties and heat source parameters in welding simulation of two overlapping beads on a substrate plate. Comp. Mater. Sci. 69, 559-565 (2013)

11. W. Piekarska, M. Kubiak, Three-dimensional model for numerical analysis of thermal phenomena in laser-arc hybrid welding process. Int. J. Heat Mass Tran. 54, 4966-4974 (2011)

12. A. Moarrefzadeh, Numerical simulation of workpiece thermal profile in Plasma Arc Cutting (PAC) Process. WSEAS Trans. Appl. Theor. Mech. 6 (4), 160-166 (2011)

13. Y. Chen, Y. He, H. Chen, H. Zhang, S. Che, Effect of weave frequency and amplitude on temperature field in weaving welding process. Int. J. Adv. Manuf. Techn. 75, 803813 (2014)

14. A. Sarkar, A. Datta, P. Dey, R. N. Rai, S. C. Saha A numerical approach for modelling thermal profiles and effects of process parameters on it in submerged arc welding of AISI 1518 grade steel. J. Therm. Eng. 1, Special Issue 3, No 6, 505 - 516 (2015)

15. M. R. Nezamdost, M. R. Nekonie Esfahani, S. H. Hashemi, S. A. Mirbozorgi, Investigation of temperature and residual stresses field of submerged arc welding by finite element method and experiment. Int. J. Adv. Manuf. Technol. 87, 615-624 (2016)

16. Z. Murčinková, K. Vasilko, Thermo-physical aspects of chip machining. High Temp. High Press. 45, 273-289 (2016)

17. O. V. Berezshnaya, E. P. Gribkov, V. D. Kuznestov, Investigation of thermostressed state coating formation at electric contact surfacing of "Shaft" type parts. Adv. Mater. Sci. Eng. ID 6597317, 14, http://dx.doi.org/10.1155/2016/6597317 (2016)

18. H. J. Jiang, H. L. Dai, Effect of laser processing on three dimensional thermodynamic analysis for HSLA rectangular steel plates. Int. J. Heat Mass Tran. 82, 98-108 (2015)

19. S. Feng, C, Huang, J. Wang, H. Zhu, P. Yao, An analytical model for the prediction of temperature distribution and evolution in hybrid laser-waterjet micro machining. Precis. Eng. 47, 33-45 (2017)

20. P. Novák; J. Meško; M. Žmindák, Finite element implementation of multi-pass fillet weld with phase changes. Manuf. Technol. 13 (1), 79-85 (2013)

21. T. Kik, M. Slováček, B. Wyględacz, Numerical analysis of multipass T-joint welding and post welding heat treatment. Weld. Technol. Rev. 88 (5), 101-106 (2016)

22. M. Patek, M. Mician, A. Sladek, D. Kadas, Numerical analysis of T-joint welding with different welding sequences. Manuf. Technol. 16 (1), 234-238 (2016)

23. R. Konar, M. Mician, M. Patek, D. Kadas, Finite element modeling and numerical simulation of welding at the repair of gas pipelines with steel sleeve. Manuf. Technol. 16 (2), 360-365 (2016)

24. R. Konar, M. Patek, M. Mician, Experimental measurements and numerical simulation of bridge construction welding at low temperatures. Communications: scientific letters of the University of Žilina 16 (3A), 130-135 (2014) 
25. A. Bokota, R. Parkitny, Modelling of thermal, structural and mechanical phenomena in hardening processes of steel elements. A. Piela [ed.]: Informatics in Metal Technology (Gliwice: Silesian Univ. Technol.), Ch. 7, 257-298 (2003)

26. E. Geissler, H. W. Bergmann, Calculation of temperature profiles heating and quenching rates during laser processing. Opt. Mag. 3, 430-434 (1987)

27. E. Geissler, H. W. Bergmann, 3D Temperature Fields in Laser Transformation Hardening, Part I: Quasi-Stationary Fields. Opt. Mag. 4, 396-403 (1988)

28. J. Winczek, R. Parkitny, Modelling of heat affected zone in submerged arc welding butt joint with thorough penetration, Procedia Engineering 177C, 241-246 (2017)

29. W. Piekarska, M. Kubiak, M. Žmindak, Issues in numerical modeling of phase transformations in welded joints. Procedia Engineering 177, 141-148 (2017)

30. W. Piekarska, D. Goszczyńska-Króliszewska, Analytical methods of predicting the structure and mechanical properties of high tensile strength steel. Procedia Engineering 177, 92-98 (2017)

31. T. Domański, A, Bokota, Numerical models of hardening phenomena of tools steel base on the TTT and CCT diagrams. Arch. Metal. Mater. 56, 325-344 (2011)

32. J. Winczek, The analysis of temporary temperature field and phase transformations in one-side butt-welded steel flats, Chapter 6 in: Joining Technologies, M. Ishak [ed.], Intech, Rijeka, Croatia 103-130 (2016)

33. J. Winczek, A. Kulawik, Dilatometric and hardness analysis of C45 steel tempering with different heating-up rates. Metalurgija 51, 9-12 (2012)

34. J. Winczek, K. Makles, M. Gucwa, R. Gnatowska, M. Hatala, Modelling of strains during SAW surfacing taking into heat of the weld in temperature field description and phase transformations. IOP Conf. Series: Materials Science and Engineering 225, 012038 doi:10.1088/1757-899X/225/1/012038 (2017)

35. J. Gawąd, D. Szeliga, A. Bator, V. Pidvysockyy, M. Pietrzyk, Interpretation of the tensile test results interpretation based on two criterion optimization. Proc. 14. Conf. KomPlasTech, Informatics in Metal Technology, M. Pietrzyk et al. [ed.], Akapit, Cracow, 27-34 (2004)

36. P. M. M. Vila Real, R. Cazeli, L. Simoes da Silva, A. Santiago, P. Piloto, The effect of residual stresses in the lateral-torsional buckling of steel I-beams at elevated temperature. J. Construct. Steel Research 60, 783-793 (2004)

37. M. Melander, A Computional and Experimental Investigation of Induction and Laser Hardening. Linkoping Studies Sci. Technol. 124, Linkoping Univeristy (1985)

38. J. Lian, Z. Jiang, J. Liu, Theoretical model for the tensile work hardening behaviour of dual-phase steel. Mater. Sci. Eng. A147, 55-65 (1991)

39. S. K. Kim, Y. M. Kim, Y. J. Lim, N. J. Kim, Relationship between yield ratio and the material constants of the swift equation. Metals Materials Int. 12 (2), 131-135 (2006) 